\title{
Response to CDR Sean Bryant Regarding "Wartime toxicology: Evaluation of a military medical toxicology telemedicine consults service to assist physicians serving overseas and in combat: 2005-2012"
}

\author{
Joseph K. Maddry • Daniel J. Sessions • \\ Vikhyat S. Bebarta
}

Published online: 24 December 2014

(C) American College of Medical Toxicology (outside the USA) 2014

CDR Sean Bryant,

Thank you for your recent service in Afghanistan and thank you for your letter. I also recently returned from deployment to Afghanistan, as have several of the other authors, and we have had similar experiences with toxicological exposures in the deployment environment. We also agree that many of our colleague physicians would benefit from the ability to rapidly consult with a toxicologist. Both during my deployment and since my return, I have had multiple consults during which I have been able to provide immediate recommendations using

a Wi-Fi chat/text application (i.e., Voxer) via my cellular phone. A military-civilian partnership using similar communication modalities could greatly enhance the ability of toxicologists to serve military, humanitarian, and other overseas operations in austere environments. We look forward to supporting this effort and would greatly appreciate coordinating with you and anyone else interested in this endeavor.

Maj. (Dr.) Joseph Maddry, USAF

Maj. (Dr.) Daniel Sessions, USA

Lt. Col. (Dr.) Vikhyat S. Bebarta, USAF

J. K. Maddry $(\bowtie) \cdot$ D. J. Sessions $\cdot$ V. S. Bebarta

San Antonio Military Medical Center, San Antonio, TX, USA

e-mail: joseph.maddry@gmail.com 